\title{
Reducing Temperature Dependence of Semiconductor Lasers Using Nonidentical Multiple Quantum Wells
}

\author{
Ching-Fuh Lin*, a,, Yi-Shin Su$u^{a}$, Di-Ku Yua , and Bing-Ruey $\mathrm{Wu}^{\mathrm{c}}$ \\ ${ }^{a}$ Institute of Electro-Optical Engineering, National Taiwan University, Taipei, Taiwan, ROC \\ ${ }^{b}$ also with Institute of Electronics Engineering and Department of Electrical Engineering, National \\ Taiwan University, Taipei, Taiwan, ROC \\ ' Telecommunication Laboratory, Chunghua Telecom Co., Ltd., Yang-Mei, Taiwan
}

\begin{abstract}
Semiconductor lasers with InGaAsP/InP nonidentical multiple quantum wells (MQWs) for optical communication are experimented to show the improved temperature characteristics. With proper layout of the nonidentical MQWs, the characteristic temperature of the laser diodes is increased. Also, the differential quantum efficiency increases to around $40 \%$ for the temperature increasing from $30^{\circ} \mathrm{C}$ to $40^{\circ} \mathrm{C}$ and approximately remains at this value for temperature above $40^{\circ} \mathrm{C}$. The reason is attributed to the carrier redistribution in the nonidentical MQWs as temperature increases. The change in temperature causes certain QWs to have increased carriers. Therefore their corresponding gain increases to overcome other effects that degrade temperature characteristics. With proper design of nonidentical MQWs, significant improvement on temperature characteristics of semiconductor lasers is possible.
\end{abstract}

Keywords: nonidentical multiple quantum wells, nonuniform carrier distribution, characteristic temperature, quantum efficiency.

\section{INTRODUCTION}

Low temperature dependence is highly desired for semiconductor lasers for low-cost optical communication. However, the conventional $\operatorname{lnGaAsP/InP}$ quantum well (QW) long-wavelength laser diodes for optical-fiber communication are very temperature-sensitive, compared to short-wavelength lasers. Many factors like nonradiative recombination, leakage currents, carrier recombination in separate confinement heterostructure (SCH) layers, and so on, usually have increasing influences with temperature ${ }^{1}$. These factors degrade laser characteristics at high temperatures. On the other hand, seldom mechanisms are found to improve temperature characteristics for semiconductor lasers except alternating material system to $\mathrm{AlGaInAs} / \mathrm{InP}^{2}$, but introducing aluminum into laser layer structure increases difficulties in epitaxy and reliability. Recent efforts using InGaAsN/GaAs still can not achieve satisfactory characteristics ${ }^{3}$. Quantum well (QW) engineering is a novel way to manipulate the bandgap energy and the quasi Fermi level at certain injection current of compound semiconductor materials. Due to the quantization nature of $Q W s$ along the epitaxial axis, complicated carrier dynamics are involved therein." Contemporary models describing carrier dynamics involve carrier diffusion/drift across the separate-confinement heterostructure $(\mathrm{SCH})$ and carrier capture/escape into or out of $\mathrm{QW}$ s. Calculations using rate equation approaches ${ }^{5}$ have shown that the carrier inside the MQW structures are not uniform. The nonuniform carrier distribution among the MQWs had also been verified experimentally. ${ }^{6}$

With the MQW structure, when laser diodes are forward biased, electrons inject from n-cladding layer and holes inject from the opposite direction. Consequently, electrons are more easily captured in QWs near n-cladding layer and holes are more likely trapped in QWs bear p-ciadding iayer, causing a nonuniform carrier distribution. Nonuniform carrier distribution inside MQW was previously considered degrading property for semiconductor lasers. However, recent works show that this nonuniform carrier distribution can be affected by $\mathrm{SCH}$ length, so that either hole or electron dominating carrier dynamics can be possibly determined ${ }^{7}$. Moreover, sequence of MQWs combined with well/harrier composition can fine tune the quasi-Fermi level of MQWs, causing desired nonuniform carrier distribution inside semiconductor optical amplifiers (SOAs) to significantly broaden the emission spectrum ${ }^{8}$. Therefore by properly

${ }^{*}$ Correspondence: Email: cflin(a)cc.ee.ntu.edu.tw; Tel: 886-2-23635251 ext. 339; Fax: 886-2-23638247

Novel In-Plane Semiconductor Lasers, Jerry R. Meyer, Claire G. Gmachl, Editors, 
designing these parameters, the nonuniform carrier distribution could be controlled for beneficial purposes. In this work, we report that proper layout of nonidentical MQWs could significantly reduce temperature dependence of InGaAsP/InP semiconductor lasers

\section{DESIGN CONCEPTS}

Here we describe the concepts required to realize the carrier distribution among the MQWs. With those concepts, how to control the nonuniform carrier distribution inside MQW can be well understood.

\subsection{Electron or Hole Dominated Carrier Transport}

Contemporary model includes carrier transport in unconfined 3D regions, whose behavior can be governed by classical diffusion/drift model in ordinary semiconductor structures. When carriers transport near the $\mathrm{QW}$ region, sequential capture/escape of $3 \mathrm{D}$ carriers into $2 \mathrm{D}$ quantized QW states takes piace. These processes all cause time delays and hence degrade the dynamic properties of MQW devices. Carrier distribution, as a steady state of carrier transport, is related to the transport delay of the carrier dynamics. The delay times can be divided into two categories: delay time of carrier transport across the unconfined 3D SCH regions (classical diffusion and drift model is considered), and delay time of 3D carrier capture into 2D QW structures ${ }^{9}, 10$ The total delay time then determines whether electrons or holes are transferred faster from 3D states into quantized 2D states, and moreover, determines the dominant carrier. Carrier capture rate is proportional to the density of states (DOS), so holes have a higher capture rate than electrons for the same QW. Therefore the delay time of holes captured into QW is shorter than that of electrons. However, due to the higher mobility of electrons, they transport faster over the SCH region than holes. Thus the delay time of electrons transport across the SCH region is shorter than that of holes. As a result, whether electrons or holes have the shorter total delay time is left undetermined.

If electrons are captured into the QWs near the n-cladding layer before holes, they will immediately induce an electric field. This field then impedes further transport of electrons to other wells and pulls holes toward the wells that electrons first reside in. This mechanism causes holes to follow the electron distribution to achieve quasi-charge neutrality condition. Thas, nomuniform carrier distribution is determined by electrons, so electrons are the dominant carriers. On the other hand, if holes reside in the QWs first, nonuniform carrier distribution is determined by holes. Then holes are the dominant carriers. The side with larger carrier concentration inside MQW is that from which the dominant carrier injects. For example, carrier concentration is higher at P-side if hole is the dominant carrier, and vice versa for electron. Detailed estimation is required to understand which type of carriers dominates the carrier distribution. The relation of total delay times of electron and hole are listed below:

$$
\begin{aligned}
& \tau_{\text {total }, n}=\tau_{n, \text { diffusion }}+\tau_{n, \text { cap }}=\frac{d_{n}^{2}}{4 D_{n}}+\tau_{n, c a p} \\
& \tau_{\text {total }, p}=\tau_{p, \text { diffusion }}+\tau_{p, c a p}=\frac{d_{p}^{2}}{4 D_{p}}+\tau_{p, c a p}
\end{aligned}
$$

Where $d_{n}$ and $d_{p}$ are the distance for electron and hole to diffuse across the QW structure, mainly the length of the SCH region; $D_{n}$ and $D_{p}$ are the diffusion coefficient of electron and hole, which depend on material component; and $\tau_{n, c a p}$ and $\tau_{p, \text { cap }}$ are the quantum mechanical capture time for electron and hole, which are generally assumed to be $1 \mathrm{ps}$ and $0.2 \mathrm{ps,}$ respectively. ${ }^{9}$ The criterion to determine the dominant carrier using total time is as follows. If the totai delay time of electron is shorter than that of hole, then electron is the dominant carrier, and vice versa for hole. The diffusion cocfficients for electron and hole depend on matcrial components. Quantum mechanical carricr capture time should also depend on material parameters (such as material ingredients and strain) and QW structures (layer structure which alters the DOS) However, the time scale seems negligible compared to classical carrier diffusion time This implies that we can decide whether electron or hole is the dominant carrier by adjusting SCH region material and SCH region length. For narrow SCH region, hole has better chance being the dominant carrier, while electron should dominate carrier distribution for wide $\mathrm{SCH}$ region. The critical SCH region length below which hole is the dominant carrier and above which electron is the dominant carrier depends also on material parameters and QW structures. 


\subsection{Gain Production from Carrier Distribution inside nonidentical MQW structure}

The uniformity of carrier distribution inside the MQW structures is determined by the injection of dominant carrier and the ability to capture carriers in each QW. The carrier distribution will be more concentrated if the QW near the dominant carrier side ( $\mathrm{n}$ - or $\mathrm{p}$-cladding side) is more able to confine carriers. On the other hand, the carrier distribution will be more uniform if the QW is more incapable of capturing carriers. From section 2.1, the ability for the QW to capture carriers is proportional to the $2 \mathrm{D}$ density of state. The relation between $3 \mathrm{D}$ unconfined DOS and the step-like 2D DOS of QW are illustrated in Fig. 1. The 2D and 3D DOS's approach the same value at the energy equal to the QW transition energy. Although the valence band DOS is not perfectly parabolic, the schematic likes Fig 1 could be drawn to explain qualitatively: For example, $\mathrm{In}_{0.53} \mathrm{Ga}_{0.47}$ As grown lattice-matched to InP substrate, the effective masses of electron and hole are smaller than $\mathrm{In}_{0.67} \mathrm{Ga}_{0.33} \mathrm{As}_{0.72} \mathrm{P}_{0.28}$ on lattice-matched InP substrate. Since effective mass indicates the curvature of 3D DOS of bulk material, 3D DOS of $\ln _{0.53} \mathrm{Ga}_{0.47} \mathrm{As}$ is smaller than $\ln _{0.67} \mathrm{Ga}_{0.33} \mathrm{As}_{0.72} \mathrm{P}_{0.28}$ under the same quantized energy, which can be adjusted with QW well thickness. In the same total injection carrier concentration, higher carrier concentration in certain QW produces higher gain for that $\mathrm{QW}$. Therefore the uniformity inside nonidentical MQW structure influences laser spectral and electrical, even thermal characteristics. For quaternary material system such as InGaAsP, one can design two kinds of QWs with different $\operatorname{In}_{1-x} \mathrm{Ga}_{\mathrm{x}} \mathrm{As} \mathrm{s}_{\mathrm{y}} \mathrm{P}_{\mathrm{i}-\mathrm{y}}$ composition but with same quantized energy and same transition energy. Hence one can alternate the 2D DOS without changing emission wavelength. Also, according to other studies, the temperature sensitivity is related not only to lasing wavelength, but also to material composition ${ }^{11}$. Therefore, with carrier distribution

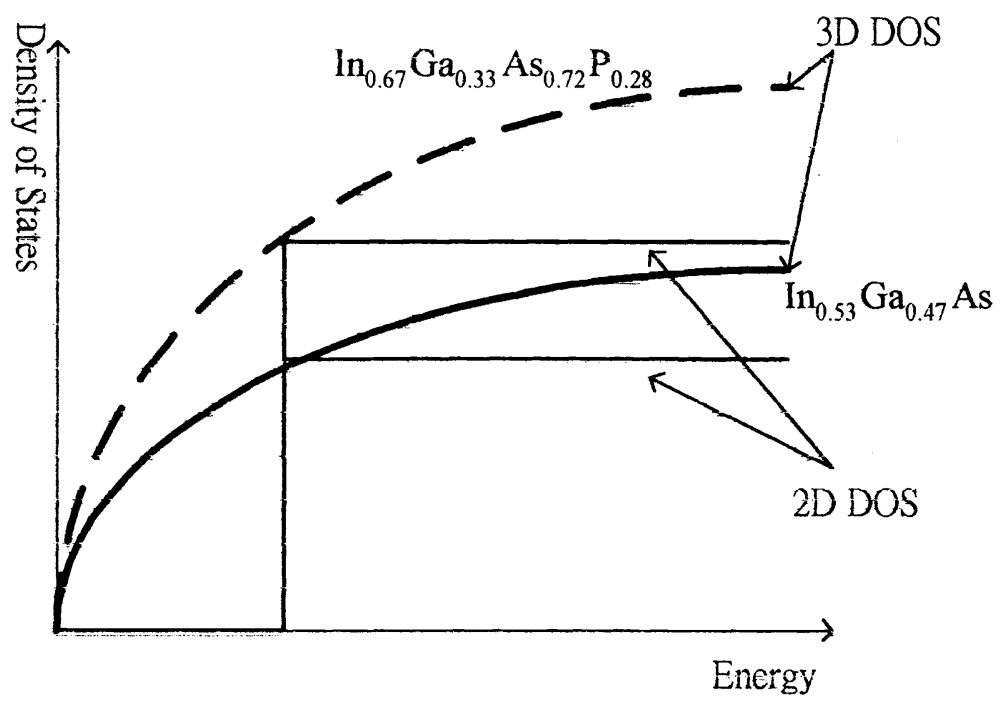

Fig. 1 Schematic diagram showing the 3D and 2D DOS of the two sets of QWs

inside MQW taken into consideration, one may design a long-wavelength laser diode less sensitive to temperature. In order to prove the concept more clearly, in this work two sets of nonidentical MQW structures with different emission wavelength is designed and described as follows.

\section{EXPERIMENT}

\subsection{Nonidentical MQW Design and Fabrication}

Layer structure of designed nonidentical MQW is shown in Fig. 2. Two sets of $M Q W s, 6 n m \operatorname{In}_{0.67} \mathrm{Ga}_{0.33} \mathrm{As}_{0.72} \mathrm{P}_{0.28}$ triple QWs (designed approximately for lasing wavelength $\lambda=1.3 \mu \mathrm{m}$ ) and $8.7 \mathrm{~nm} \operatorname{In}_{0.53} \mathrm{Ga}_{0.47}$ As double QWs (designed approximately for $\lambda=1.55 \mu \mathrm{m}$ ), form the basic components of the nonidentical MQW structure. Sample $A$ has the $\mathrm{In}_{0.53} \mathrm{Ga}_{0.47}$ As double QWs near the p-cladding layer. Sample $\mathrm{B}$ has the QWs arranged in an opposite sequence. The QW's are bounded by $15 \mathrm{~nm}^{\mathrm{In}} \mathrm{n}_{0.86} \mathrm{Ga}_{0.14} \mathrm{As}_{0.3} \mathrm{P}_{0.7}$ barrier and the $\mathrm{SCH}$ region is $120 \mathrm{~nm}$ with the same component as barrier. Detailed calculations of the cmission spectra using Luttinger-Kohn method, ${ }^{12}, 13$ show that the transition energies of the $8.7 \mathrm{~nm} \mathrm{In}_{0.53} \mathrm{Ga}_{0.47} \mathrm{As}$ double QWs are $1.54 \mu \mathrm{m}, 1.46 \mu \mathrm{m}$, and $1.18 \mu \mathrm{m}$. The transition energies of the $6 \mathrm{~nm}$ 
$\mathrm{In}_{0.67} \mathrm{Ga}_{0.33} \mathrm{As}_{0.72} \mathrm{P}_{0.28}$ triple QWs are $1.30 \mu \mathrm{m}$ and $1.24 \mu \mathrm{m}$.

The nonidentical MQW structures are grown on InP substrate with lattice-matched condition by metal-organic chemical vapor deposition (MOCVD) method. The grown nonidentical MQW structures are then used to fabricate ridgewaveguide laser diodes (LDs) by standard processing procedures. The ridge waveguide was created by the technique of electron cyclotron resonance-reactive ion etch (ECR-RIE). The etching was stopped at $\sim 100 \mathrm{~mm}$ above the SCH layer. The devices are about $500 \mu \mathrm{m}$ long.

Sample I

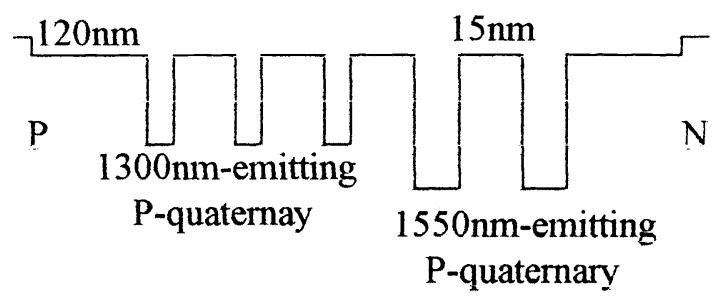

Sample II

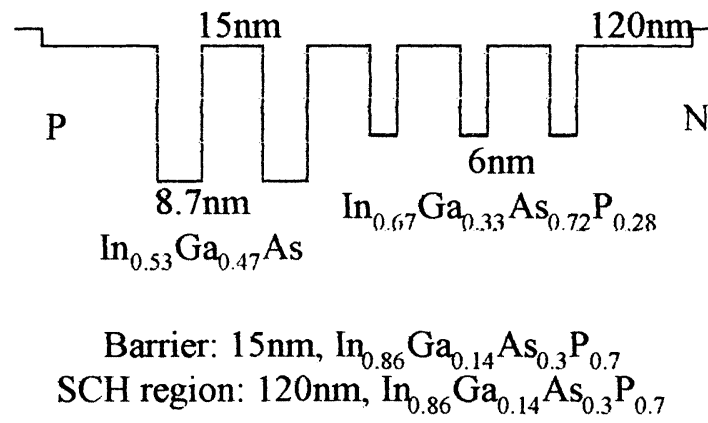

Fig. 2 Layer structures of nonidentical MQW for Sample I and Sample II

\subsection{Device Characteristics}

Optical characteristics such as lasing spectra and light-output power relations under temperature varying from $20^{\circ} \mathrm{C}$ to $55^{\circ} \mathrm{C}$ are measured on fabricated devices. The L-I curves are measured in pulsed operation with $0.5 \%$ duty cycle. More than 10 laser diodes of each well sequence had been measured and demonstrated similar behavior. The results are shown in Fig. 3(a). Also the threshold currents under different temperatures are plotted in Fig. 3(b). In Fig. 3(b) one characteristic temperature can not be derived due to the imperfect curve fitting between $30^{\circ} \mathrm{C}$ and $40^{\circ} \mathrm{C}$. The characteristic temperature below $30^{\circ} \mathrm{C}$ is $19.13 \mathrm{~K}$, which is poor like the conventional long-wavelength semiconductor laser temperature characteristics. However, for temperature above $30^{\circ} \mathrm{C}$, the temperature characteristics improve significantly to $51.34 \mathrm{~K}$. The external quantum efficiency $\left(\eta_{d}\right)$ under different temperature extracted from Fig. 3(a) is shown in Fig. 4. Under all measured temperatures, $\eta_{i}$ of Sample II is higher than that of Sample I. For Sample I, $\eta_{i}$ decreases with temperature for the entire measured temperature range, which is similar to the behavior of conventional LDs. With increasing temperature, the lasing efficiency of conventional laser diodes fall due to various factors like nonradiative recombination, leakage currents, carrier recombination in SCH layer, etc. However, for sample II, novel variation of $\eta_{d}$ with temperature is observed. It first decreases from $41 \%$ to $37 \%$ for the temperature varying from 20 ${ }^{\circ} \mathrm{C}$ to $30^{\circ} \mathrm{C}$. Then $\eta_{d}$ increases again to around $40 \%$ and approximately remains at this value for temperatures above 
$40^{\circ} \mathrm{C}$. The above measurements show that the temperature dependence of threshold current and quantum efficiency could be reduced for certain sequence of nonidentical MQWs.
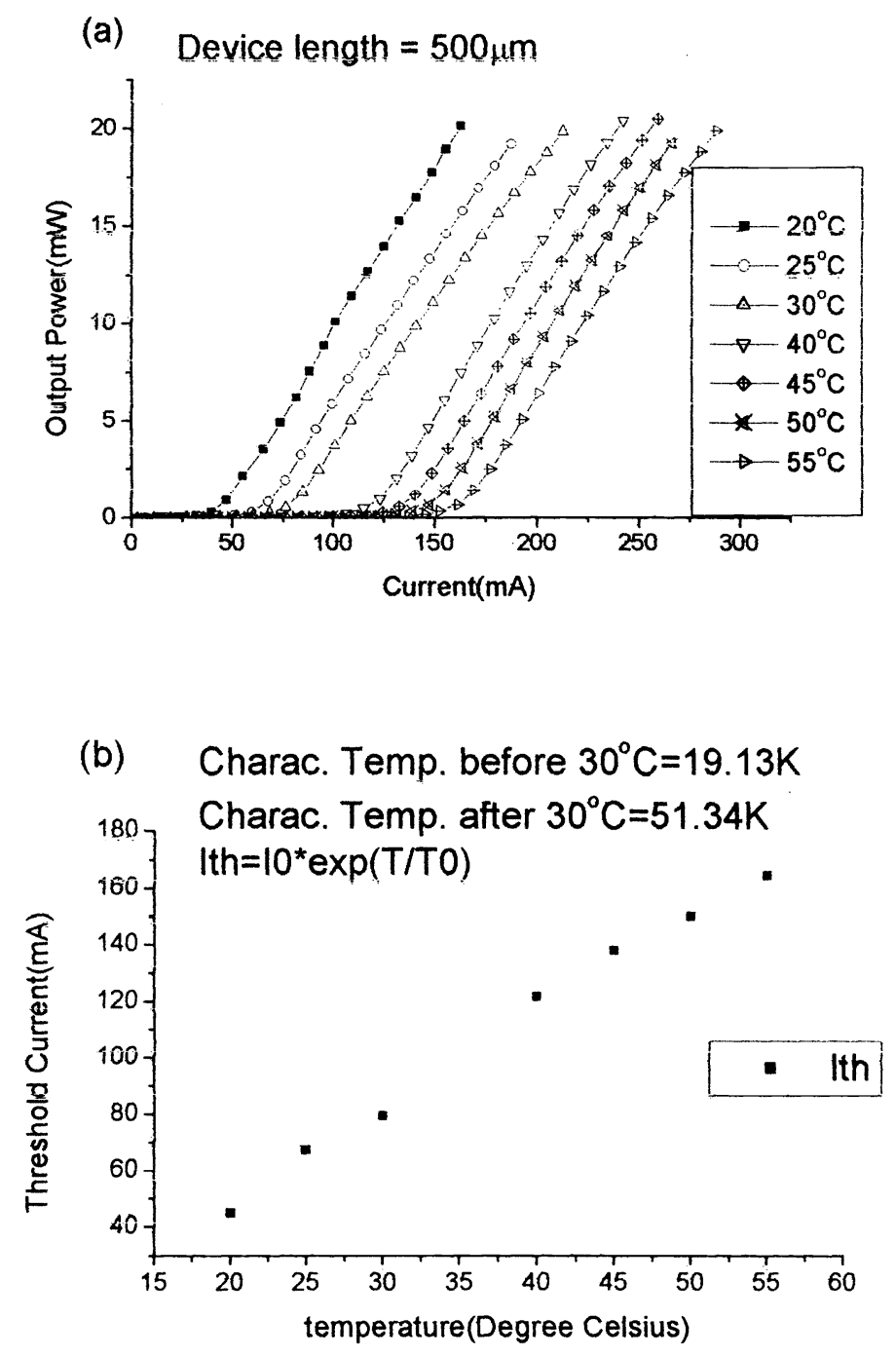

Fig. 3 (a)L-I relation (b)Threshold currents of Sample I measured in different temperatures.

To further realize the novel behavior of temperature characteristics, the variation of lasing wavelength with temperature is also measured. Fig. 5 shows the variation of the lasing wavelength with temperature for the two samples. The lasing spectra of Sampie I and Sampie II under room temperature are about $1500 \mathrm{~nm}$ and $1417 \mathrm{~nm}$, respectively. The resuiting lasing spectra can be regarded as due to the superposition of gain profiles of both $1.3 \mu \mathrm{m}$ and $1.55 \mu \mathrm{m}$ QWs. For Sample $1,1.55 \mu \mathrm{m}$ QW accumulate more carriers than $1.3 \mu \mathrm{m}$ QWs, so the gain from $1.55 \mu \mathrm{m} \mathrm{QWs}$ is larger. Thus its lasing mode is mainly contributed from the $87 \AA$ QWs. Similarly, the lasing wavelength of Sample II indicates that both the $60 \AA$ QWs and the $87 \AA$ QWs contribuite gain to the lasing mode. Considering the sequential layout of QWs, the measured lasing spectra imply that more carriers are trapped in QWs near n-side For conventional LDs with QWs of the same width, increasing temperature usually results in a red shift of wavelength because of bandgap shrinkage. In this investigation, the IDs with nonidentical QWs behave oppositely. The increase of temperature causes a blue shift of lasing wavelength for both Sample I and Sample II. In particular, the blue shift of Sample II is quite significant. Its lasing wavelength shifts from $1417 \mathrm{~nm}$ to $1370 \mathrm{~nm}$, nearly $50 \mathrm{~nm}$, for temperature changing from $25^{\circ} \mathrm{C}$ to $45^{\circ} \mathrm{C}$. 
The reason for the blue shift is because some portion of carriers originally in $1.55 \mu \mathrm{m}$ QWs move over to $1.3 \mu \mathrm{m}$ QWs when temperature increases. For Sample I, $1.55 \mu \mathrm{m}$ QWs are near $\mathrm{n}$-side, so carriers move from n-side toward pside. The change of carriers from $1.55 \mu \mathrm{m}$ QWs to $1.3 \mu \mathrm{m}$ QWs is not significant enough, so the lasing wavelength remains near $1500 \mathrm{~nm}$, still mainly contributed from the $1.55 \mu \mathrm{m}$ QWs. However, such carrier change is already large enough to induce sensitive temperature dependence, causing the threshold current and quantum efficiency to vary significantly with temperature.

\section{External quantum efficiency of both facet}

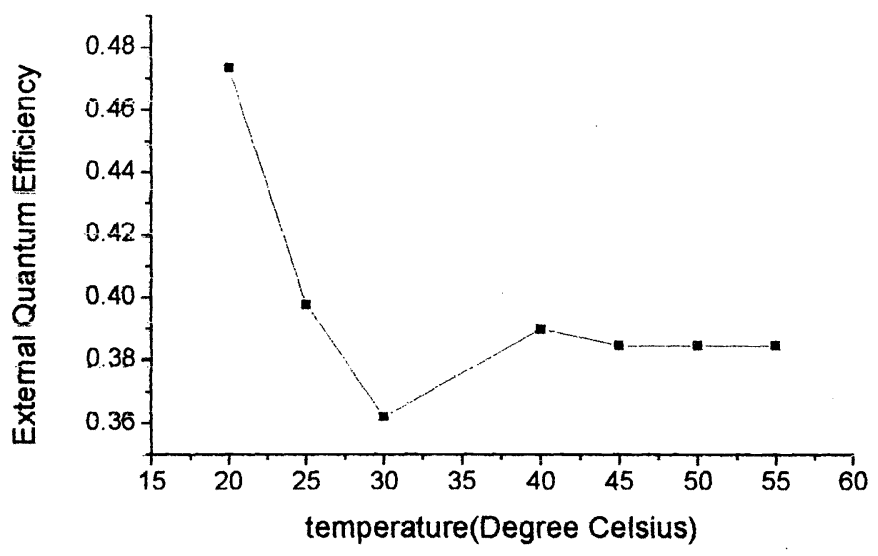

Fig. 4 External quantum efficiency of Sample I under temperature from $20^{\circ} \mathrm{C}$ to $55^{\circ} \mathrm{C}$

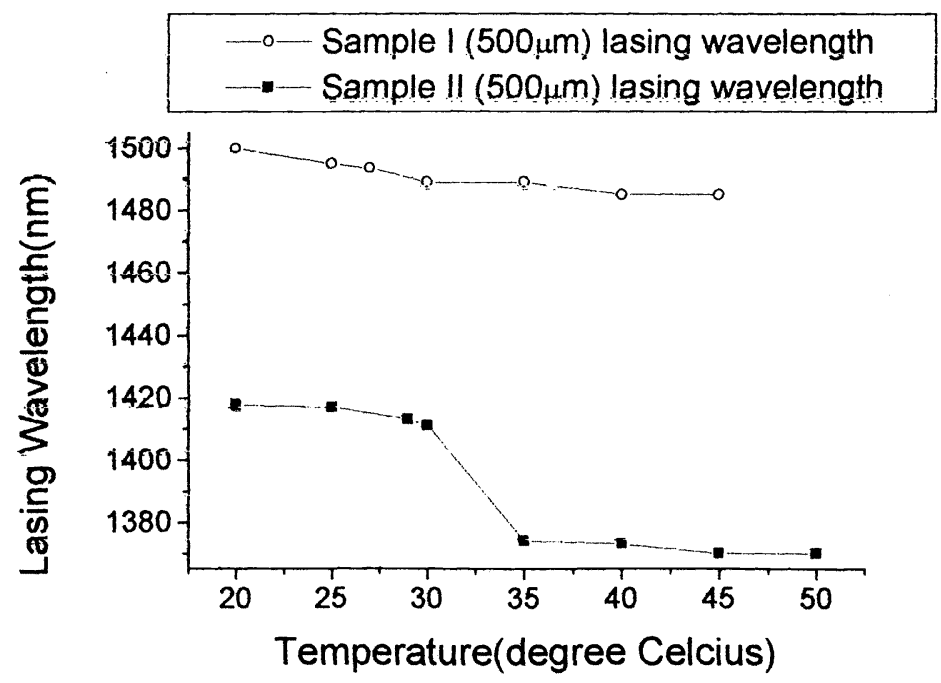

Fig. 5 variation of lasing wavelengths vs. temperature for Sample I and Sample II.

The abrupt changes in characteristic temperature and external quantum efficiency represent transition of lasing state. Shown in Fig. 6 is the output power at $1417 \mathrm{~nm}$ and $1370 \mathrm{~nm}$ vs. temperature. This figure shows in normalized 
output power for individual lasing wavelength. The lasing wavelength changes abruptly from $1417 \mathrm{~nm}$ at temperature of $30^{\circ} \mathrm{C}$ to $1370 \mathrm{~nm}$ at temperature higher than $35^{\circ} \mathrm{C}$. A $47 \mathrm{~nm}$ lasing wavelength switch is controlled by temperature variation of $5^{\circ} \mathrm{C}$. And the output power transfers totally within $10^{\circ} \mathrm{C}$ range, from $30^{\circ} \mathrm{C}$ to $40^{\circ} \mathrm{C}$. The abrupt lasing wavelength change results from gain competition between $8.7 \mathrm{~nm} \quad \mathrm{In}_{0.53} \mathrm{Ga}_{0.47} \mathrm{As}$ double QWs and the $6 \mathrm{~nm}$ $\mathrm{In}_{0.67} \mathrm{Ga}_{0.33} \mathrm{As}_{0.72} \mathrm{P}_{0.28}$ triple QWs.

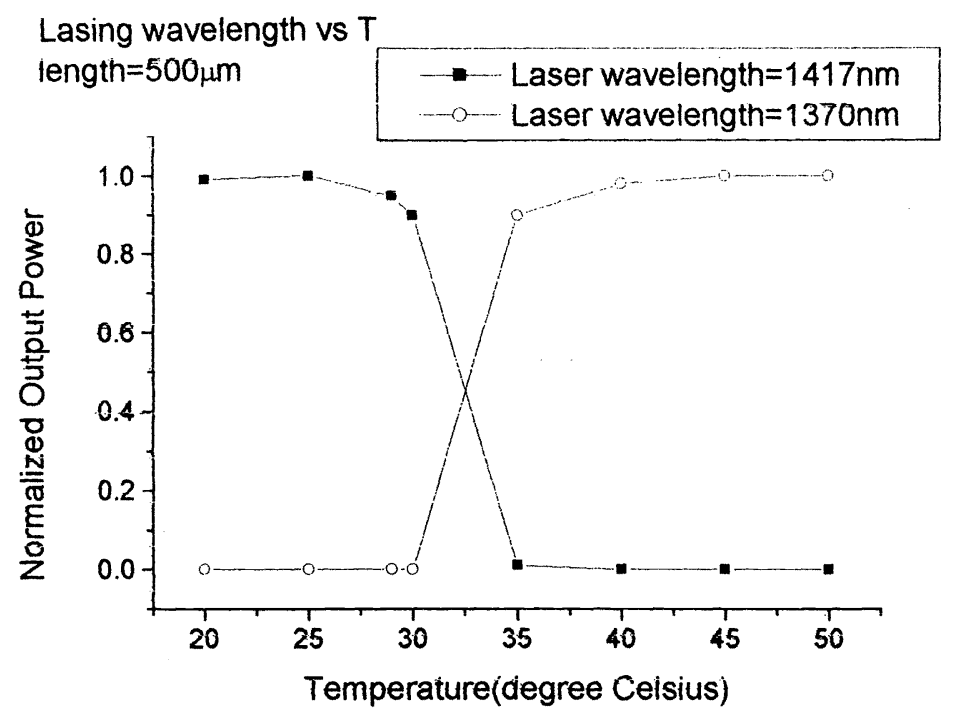

Fig. 6 Measured lasing wavelength vs. temperature of Sample II LDs

\section{DISCUSSION}

Table I shows the calculation result of $n=1$ transition energy and effective mass of the two sets of MQWs used in Sample A. Note that the QW corresponding to longest emission wavelength always has the highest gain under the same carrier density in each well. Therefore the $\mathrm{QW}$ with shorter emission wavelength needs more carrier concentration to obtain enough gain in order to achieve threshold condition. Fig. 5 shows the lasing wavelength as a result of superposition of nonidentical MQW gain spectra. From previous researches, it was shown that this MQW structure is dominated by electron due to the long $\mathrm{SCH}$ region. As a result, more carriers accumulate in the QWs near the $\mathrm{n}$ cladding layer, which correspond to the wavelength of $1.3 \mathrm{Hm}$ QWs. Consequently the gain spectrum of each set of QWs is nearly the same and the laser diodes oscillate at wavelengths between $13 \mu \mathrm{m}$ and $1.55 \mu \mathrm{m}$ As a matter of fact, the lasing wavelength is closer to $1.55 \mu \mathrm{m}$ because the $1.55 \mu \mathrm{m}$ QWs need a lower gain to achieve lasing condition.

When temperature increases, the nonuniformity of carrier distributing inside nonidentical MQW changes, possibly due to more scattering event experienced by carriers. In addition, this change causes the lasing wavelength to shift toward 1.3 $\mu \mathrm{m}$ QWs. Also for the nonidentical MQW, a slight change in carrier concentration in certain QWs may change the total gain spectrum abruptly. Therefore the competition for achieving threshold gain between $1.3 \mu \mathrm{m}$ and $1.55 \mu \mathrm{m} \mathrm{QWs}$ is dorrinated by $1.3 \mu \mathrm{m} \mathrm{QW}$ when temperalure increases.

When temperature increases, the change of lasing wavelength from $1417 \mathrm{~nm}$ to $1370 \mathrm{~nm}$ indicates that the QWs of $1.3 \mu \mathrm{m}$ gets more carriers than $1.55 \mu \mathrm{m}$ QWs. The reason for carriers in $1.3 \mu \mathrm{m}$ QWs increasing with temperature is explained as follows. When temperature increases, more carriers occupy larger energy states according to Fermi-Dirac distribution, so they can be more possibly captured by $1.3 \mu \mathrm{m}$ QWs than by $1.55 \mu \mathrm{m}$ QWs. Thus the gain contributed 
Table I The $n=1$ transition energy and effective mass of electron and heavy hole of the two sets of QWs

\begin{tabular}{|l|l|l|}
\hline The emission wavelength designed & $1.55 \mu \mathrm{m}$ & $1.3 \mu \mathrm{m}$ \\
\hline Quantum well material & $\operatorname{In}_{0.53} \mathrm{Ga}_{0.47} \mathrm{As}$ (Double QWs) & $\mathrm{In}_{0.67} \mathrm{Ga}_{0.33} \mathrm{As}_{0.72} \mathrm{P}_{0.28}$ (Triple QWs) \\
\hline Quantum well width & $87 \AA$ & $60 \AA$ \\
\hline Emission wavelength from our simulation & $1.54 \mu \mathrm{m}$ & $1.3 \mu \mathrm{m}$ \\
\hline $1^{\text {st }}$ quantized state of conduction band & $53.22 \mathrm{meV}$ & $52.58 \mathrm{meV}$ \\
\hline $1^{\text {st }}$ quantized state of valence band & $9.17 \mathrm{meV}$ & $14.34 \mathrm{meV}$ \\
\hline Conduction band effective mass & $0.041 \mathrm{~m}_{0}$ & $0.052 \mathrm{~m}_{0}$ \\
\hline Valence band effective mass (Heavy hole & $0.42 \mathrm{~m}_{0}$ & $0.47 \mathrm{~m}_{0}$ \\
\hline
\end{tabular}

from $1.3 \mu \mathrm{m}$ QWs increases, resulting in the blue shift of lasing wavelength. In addition, the nonuniform carrier distribution favoring QWs near n-side, which are $1.3 \mu \mathrm{m}$ QWs for Sample II, causes the blue shift of Sample II to be very significant.

According to the less temperature-sensitive nature of $1.3 \mu \mathrm{m} \mathrm{QW}$, the temperature sensitivity of laser diode is reduced. Based on the novel discovery long-wavelength laser diodes can be designed by using different QW with different temperature sensitivity inside active region, without change in lasing wavelength.

\section{CONCLUSION}

Using nonidentical MQWs structure, temperature sensitivity of long-wavelength semiconductor lasers can be efficiently reduced. A characteristic temperature increase from $19.13 \mathrm{~K}$ to $51.34 \mathrm{~K}$ with temperature change from $30^{\circ} \mathrm{C}$ to $40^{\circ} \mathrm{C}$ is observed. Aiso the lasing wavelength within this temperature change is abrupt, impiying change in nonuniform carrier distribution. With the less temperature-sensitive $\mathrm{QW}$ located in the proper location, significant improvement on temperature characteristics of semiconductor lasers is possible.

\section{ACKNOWLEDGEMENTS}

The authors acknowledge the support from National Science Council, ROC under the contract NSC89-2112-M002-076 and NSC89-2215-E-002-059.

\section{REFERENCES}

1. H. Ishikawa and I. Suemune, "Analysis of temperature dependent optical gain of strained quantum well taking account of carriers in the SCH layer," IEEE Photon. Technol. Lett., vol. 6, pp. 344-347, 1994.

2. C. E. Zah, R. Bhat, B. N. Phatak, F. Favire, W. Lin, M. C. Wang, N. C. Andreadaskis, D. M. Huang, M. A. Koza, T. P. Lee, Z. Wang, D. Darby, D. Flanders, and J. J. Hsieh, "High performance uncooled $1.3 \mathrm{Im} \mathrm{Al}_{\mathrm{x}} \mathrm{In}_{\mathrm{y}} \mathrm{Ga}_{1-\mathrm{x}-}$ ${ }_{y} \Lambda s / I n P$ strained layer quantum well lasers for subscriber loop applications," IEEE J. Quantum Electron., vol. 30, pp. 511-522, 1994.

3. K. Nakahara, M. Kondow, T. Kitatani, M. C. Larson, and K. Uomi, "1.3-цm Continuous-Wave Lasing Operation in GaInNAs Quantum-Well Lasers," IEEE Photon. Technol. Lett., vol. 10, pp. 487-488, 1998.

4. N. Tessler and G. Eisenstein, "On carrier injection and gain dynamics in quantum well lasers", IEEE J. Quantum Electron., vol. 29, pp.1586-1595, 1993.

5. N. Tessler and G. Eisenstein, "Distributed nature of quantum well lasers," Appl. Phys. Lett., vol. 63, pp. 10-12, 1993.

6. B. R. Wu, C. F. Lin, L. W. Laih, and T. T. Shih, "Extremely Broadband InGaAsP/InP Superluminescent Diodes," IEE Electron. Lett. 36, pp. 2093-2095, 2000.

7. B. R. Wu, C. F. Lin, L. W. Laih, T. T. Shih, "Characteristics of Laser Diodes Influenced by Electron-dominant 
Nonuniform Carrier Distribution," SPIE Proceedings, Vol. 4283 (Physics and Simulation of Optoelectronic Devices (X), pp. 659-669, 2001.

8. C. F. Lin, B. R. Wu, L. W. Laih, and T. T. Shih, "Sequence Influence of Nonidentical InGaAsP Quantum Wells on Broadband Characteristics of Semiconductor Optical Amplifiers' Superluminescent Diodes," Opt. Lett. 26, pp. $1099-1101,2001$.

9. M. Alam and M. Lundstrom, "Simple analysis of carrier transport and buildup in separate confinement heterostructure quantum well lasers", JEEE Photon. Technol. Lett., vol. 6, pp. 1418-1420, 1994

10. D. Tauber and J. E. Bowers, "Dynamics of wide bandwidth semiconductor lasers," from High Speed Diode Lasers, Editor: S. A. Gurevich, pp. 1-40, World Scientific, Singapore, 1998.

11. K. Otsubo, H. Shoji, T. Kusunoki, T. Suzuki, T. Uchida, Y. Nishijima, K. Nakajima, and H. Ishikawa, "LongWavelength Strained Quantum-Well Lasers Oscillating up to $210^{\circ} \mathrm{C}$ on InGaAs Ternary Substrates," IEEE Photoni. Fechnol. Lett., Vol. 10, pp. 1073-1075, 1998

12. J. M. Luttinger and W. Kohn, "Motion of electrons and holes in perturbed periodic fields," Phys. Rev. 97, pp. 8698831955.

13. D. Ahn and S. L. Chuang, 'Optical gain and gain suppression of quantum well lasers with valence band mixing', IEEE I. of Quantum Electron., vol. 26, pp. 13-24, 1990 